\section{La condición digital de la imagen gráfica}

The Digital Condition of the Graphic Image

Ronald Fernando Meléndez

Cardona

Rubén Tortosa Cuesta

Palabras clave: arte digital artes gráficas, nuevos medios, medios tradicionales, new memory

Key words: digital art

graphic arts, new media, tra-

ditional media, new memory
La tecnología digital ha otorgado sin duda nuevas posibilidades creativas a la imagen gráfica, fundamentalmente, como consecuencia de la condición electrónica y virtual de su medio. Si consideramos plenamente lo digital como tecnología, podemos afirmar que toda imagen producida o mediada a través del afirmar que toda imagen producida o mediada a traves del computador es en principio digital. No obstante, si consideramos lo digital como expresión, podemos observar que no todas las imágenes producidas o mediadas por el computador expresan "digitalidad". A partir de un análisis de los conceptos "digital" y "gráfica" se desarrolla un argumento que propone entender una supuesta naturaleza digital de la imagen gráfica.

Digital technology has certainly given new creative possibilities to the graphic image, mainly as a result of the electronic and virtual condition of its medium. If we fully consider digital as technology, we can say that every image produced or mediated through computer is essentially digital. However, if we consider the digita as expression, we may observe that not all the images produced or mediated through computer express "digitality". Based on the analysis of the "digital" and "graphic" concepts an argument will be developed that proposes an understanding of an alleged digital nature of the graphic image.
1 Lev Manovich utiliza la expresion "Permanent Extendibility" para definir una de las cualidades fundamentales tos medios computacionales constiposibilidad de agregarles continuamente nuevas propiedades. Esto permite que sus capacidades expresivas se extienda constantemente como medio técnico múltiple sin modificar su substancia física:" To add new properties to physical
media requires modifying their physical media requires modifying their phys
substance. But since computationa substance. But since computational
media exists as software, we can add media exists as software, we can add
new properties or even invent new types software, writing new software, adding plug-ins and extensions, or by putting existing soffware together $[$, I" (L MA NOVICH, "New Media." En: B. PERRON ed.), M. J. P.Wolf (ed.), The Video Game Theory Reader 2, p. 371

2 Las implicaciones que pueda tener esta condición en la expresividad de la imagen gráfica se fundamentará principalmente en la levedad material causada por la sustitucion, en terminos el bit: "A bit has no color, size, or weigh and it can travel at the speed of light." (N. NEGROPONTE, Being digital, p. 14 . a introducción de esta inmaterialidad ámbito de la creación gráfica, ha puesto en cuestión algunos de los valores expresivos característicos de su lenguaje, desvirtuando muchos de sus conceptos 0 , probablemente, haciendo necesario ataber uno nuevos, consecuenci hora de una naturaleza intangible y mutable que se opone al pesado y denso gráfica ha sustentado gran parte de su y materiales para la representación. producción y la estampación y que ha constituido signo intrínseco de su condición como medio de producción. Es por ello que la inmaterialidad ha sido uno de los aspectos fundamentales en exploración de la imagen grafica -y expresion artistica-dentro del medio conceptos propios de su medio como huella o matriz (véase: HAYVAERT A CHAUDOUËTY. (CURAT.), De la huella a o numérico. Vigo: Universidad de Vigo, 2010. 293 p.) como de las propiedades específicas que produce su intangibilidad electrónica Ivéase: ALCALA J. R La piel de la imagen: ensayos sobre gráfica en la cultura digit
La tecnología digital no solo ha permitido introducir dentro de los procesos de creación visual nuevas técnicas para la reproducción de la imagen gráfica, sino que ha permitido generar nuevas posibilidades expresivas en los procesos de su producción, las cuales han sido en parte consecuencia de una "extensibilidad permanente"1 propia de la naturaleza "inmaterial" de un medio que se constituye fundamentalmente por su condición electrónica². La representación gráfica digital ha adquirido de esta manera valores estéticos que han permitido identificar la mediación del computador como máquina y herramienta Dichos valores han podido reconocerse tanto en los trabajos de autores pioneros en el uso del computador como Manfred Mohr, Charles Csuri, April Greiman o David Carson, como en las pixeladas imágenes de los videojuegos de ocho bits, las representaciones poligonales de una imagen en $3 \mathrm{D}$ o las abstractas y complejas formas gráficas que a través del computador han permitido visualizar las teorías fractales de Mandelbort o las estructuras rizomáticas y constantemente mutables del ciberespacio.

No obstante, sin negar las extensas y complejas incidencias que la tecnología digital ha tenido dentro de la creación visual y la expansión de conceptos como la gráfica múltiple ${ }^{3}$, puede pensarse que la expresión de "lo digital" no es propiamente la consecuencia tecnológica de un medio -aunque este haya afectado su entendimiento- ya que no todas las imágenes mediadas por el computado revelan propiamente una "apariencia digital" sino más bien cualidades expresivas producidas a través de técnicas tradicionales como el fotomontaje, la sobreimpresión, el décollage o el movimiento, por mencionar algunos ejemplos ${ }^{4}$. Por lo tanto, se plantea que lo digital experimentado dentro de los ámbitos de la comunicación visual, no responde principalmente a una razón tecnológica sino a una cualidad expresiva inherente a la naturaleza de medios que, como en el caso de la gráfica, conforman sistemas indirectos de creación, y que al
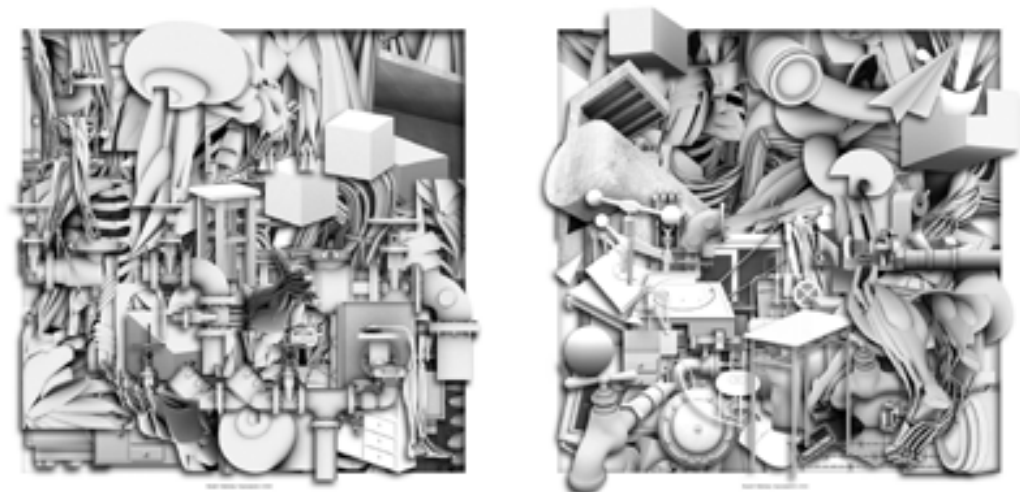

Fig. 1 "Improvisación I" e "Improvisación II". Modelado 3D y edición digital. Versión impresa de 90 × $90 \mathrm{~cm}$ c/u. Ronald Meléndez. 2013 

convergencia con otros medios son algunas de las posibilidades que el computador ha otorgado a la creación gráfica en su extensión como medio de expresión, se busca principalmente en este análisis indagar qué es lo que implica lo digital como elemento exuna no. En esta medida, se presum valores ya existentes que revitalicen una comprensión de su medio no propiamente como un asunto tecnológico, lo cual puede aparentemente hacer necesario que, parte de una llamada expresion digital, requiera un reintegración de recursos formales y conceptuales previos a su desarrollo. 4 Muchas de estas propiedades que a cor claramente expuestas a partir movimientos como el constructivismo. Véase por ejemplo los fotomontajes de EI Lissitzky o los efectos compositivos de transparencia producidos por las sobreimpresiones de texto e image de Piet Zwart. Sin embargo, puede verse ya desde las tecnicas del papier collé cubista, o el collage dadaísta, problemas de "edición" de la imagen sobre los que se sustenta ampliamende creación gráfica.

5 Tal como señala. Moro. "conceptos formativos como de reiteración de la imagen, secuencialidad, fragmentación, acumulación módulo, superposición icónica, interferencia icónica o apropiación, todos ellos presentes (aunque en algunos casos de forma latente) en la práctic habitual en grabado y estampación desde hace siglos, hasta el punto de que son parte de su idiosincria MARTÍNEZ MORO, Un ensayo sobre grabado, p.20), forman parte ahora de las posibilidades expresivas que el me dio digital facilita técnicamente como medio de producción visual. 6 R. POYNOR, No más normas: dise ño gráfico y posmoderno, p. 115. 7 Lev Manovich ya desmitticaba algnas de las condiciones sobre las que lo digital era comprendido como nuevo cine, señalaba que ya contenía princi pios como "la representación discre el acceso aleatorio, el multimedia.. (L. MANOVICH, El lenguaje de los nue vos medios de comunicación, p. 99). 8 Con el propósito de continuar estar fundamentados en la duplicación, han favorecido históricamente recursos expresivos que forman parte ahora de las potencialidades del repertorio digital tales como la acumulación, la superposición, la fragmentación, la división, la repetición u otras formas -todas ellas producidas ahora por operaciones básicas del computador como copiar y pegar- exploradas ya de manera extensa, bajo otras condiciones, en la creación gráfica ${ }^{5}$. (Fig. 1.)

Dado entonces que, de acuerdo a esta hipótesis, muchos de los valores estéticos sobre los que se ha constituido la imagen gráfica digital, en los que "la complejidad, fácilmente alcanzable, y el exceso gráfico se han convertido en la norma" ${ }^{6}$, no corresponden propiamente a cualidades únicas del medio ${ }^{7}$, se considera necesario cuestionar la "gráfica digital" desde una perspectiva que permita revalorar su entendimiento como medio de expresión por fuera de su comprensión plena e inmediata como denominado medio tecnológico.

Si bien este ejercicio ha sido ya parte importante de las reflexiones que sobre la creación artística y visual ha tenido la comprensión de los medios, es claro que como un nuevo medio, su comprensión -y liberación- como nueva forma aún está en desarrollo, motivo por el cual se hace necesario cuestionar sus especificidades dentro de los distintos ámbitos de producción. Partiendo entonces de lo digital como un valor que no se produce propiamente por un medio tecnológico, sino como algo que en sí constituye una cualidad expresiva, se plantea que la imagen gráfica -sin considerar aquí específicamente un ámbito de producción (arte o diseño)- es por naturaleza digital y por ello su expresividad como "lenguaje digital" no ha estado condicionada a esta última tecnología. Teniendo en cuenta de esta manera que gran parte de los valores expresivos que se le ha atribuido presuntamente no son concedidos propiamente por el medio, se plantea que lo digital no solo es una cualidad que inherentemente se encuentra vinculada a la gráfica sino que puede producirse además dentro de medios comúnmente entendidos como analógicos.

\section{Una aproximación conceptual}

Dado que este análisis constituye parte del proceso de una investigación que busca indagar las posibles particularidades que otorga el medio digital a la expresión gráfica ${ }^{8}$, se plantea aquí un análisis preliminar de los conceptos "digital" y "gráfica" -desde sus respectivas particularidades y en torno a cualidades expresivas- con el propósito de hallar similitudes o puntos de convergencia que permitan valorar la naturaleza digital de la imagen gráfica. Se revisará primero la definición del término digital, fundamentalmente como un concepto que se opone a lo analógico y luego se revisarán las particularidades de la gráfica como medio indirecto de creación para determinar de esta manera las cualidades que presentan dentro de una llamada gráfica digital. Se pretende de esta manera establecer una base que permita determinar que el lenguaje gráfico

Fig. 2 "Píxeles aleatorios". Lápiz sobre papel logarítmico. $27.9 \times 21.5 \mathrm{~cm}$. Ronald Meléndez. 2008

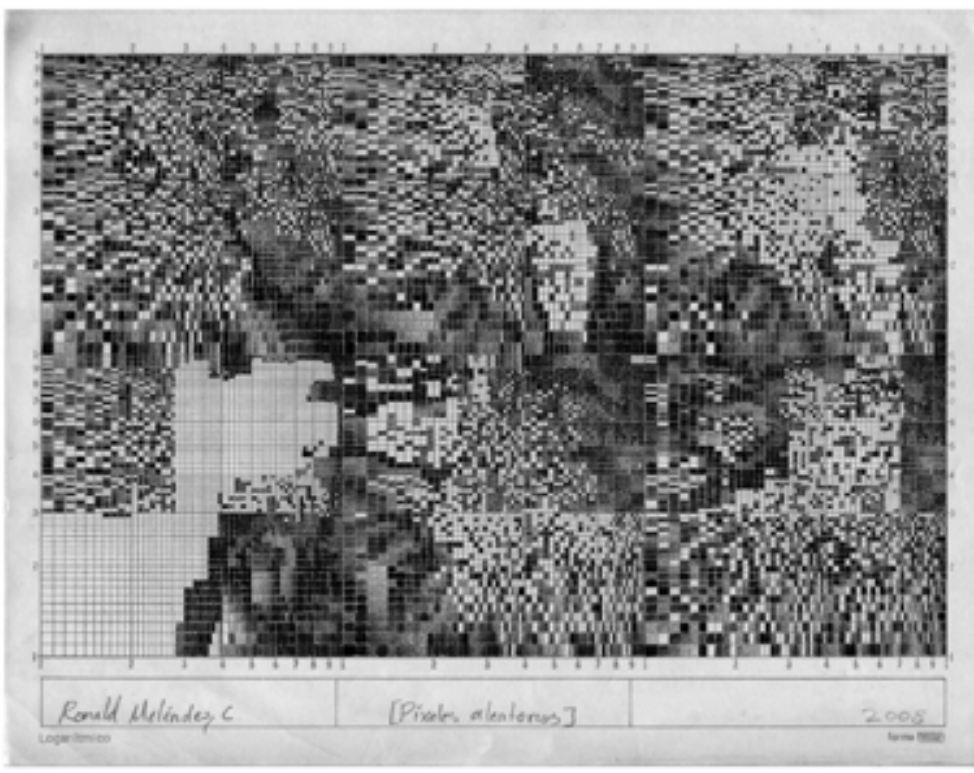

dentro de esta actividad reflexiva, que indudablemente promueve la investigación de nuevas formas de ende creación y que conduce a una constante interpretación de las condiciones sobre las que un lenguaje de expresion se constituye, se plantea aquí una indagación preliminar que surge como parte del proceso llevado actualment e influencia de los videoju eos en arte: una propuesta para la exploracion y entendimiento de las particularidades expresivas del medio digital como herramienta de representación gráfica" 9 En esta medida, el computador no está definido propiamente como medio por ser digital, sino por los contenidos que posee como nuevo medio constituido por software. En la tecnología digital, el medio los programas que contiene, razón por la cual, lo digital, como expresión, es ocultado por las formas de simulacio que los programas, en este caso part cular, de creación gráfica, producen en su necesidad de reproducir el mundo analógico. No obstante, como bien expresa Marshall McLuhan, "este hecho, caracteristico de todos los medios, significa que el 'contenido' de todos y cualquiera de ellos es siemp comprensión de los medios como extensiones del hombre, p. 30 . es expresivamente digital y se plantea eventualmente cuestionar qué es lo nuevo que la tecnología digital otorga a la creación gráfica fuera de sus alcances técnicos. (Fig. 2.)

\section{Lo digital como elemento expresivo}

Una primera consideración, tiene que ver propiamente con el entendimiento de lo digital dentro de los ámbitos comunes de la creación, ya que si bien, en términos generales, puede decirse que la tecnología digital se basa en una codificación electromagnética de datos a partir de dos niveles de voltaje, definidos simbólicamente dentro de un sistema numérico representado por bits (binary digits), su significado como medio de representación visual, adquiere relevancia más allá de las condiciones técnicas a través de la cual se constituye intrínsecamente como tecnología, más aun, cuando como instrumento de creación, se encuentra convencionalmente mediado por interfaces gráficas $^{9}$ sobre las que se construyen los entornos virtuales de producción que ocultan su discreto "estado de ser: encendido o apagado, verdadero o falso, arriba o abajo, dentro o fuera, negro o blanco" ${ }^{10}$. Es por ello que técnicamente es más común entender lo digital como un concepto que se contrapone o que es distinto a lo analógico, dado que lo analógico, dentro del ámbito de la creación visual, habitualmente se asocia a formas de producción que se sustentan en medios tradicionales mientras que lo digital se asocia a los "nuevos medios", lo cual determina de alguna manera una comprensión más inmediata de sus respectivos productos como efecto de la mediación.

En consecuencia, lo analógico, comúnmente se ha entendido como algo que constituye naturalmente los medios anteriores a la tecnologia digital y lo digital como algo que es inherente al computador. 
10 N. NEGROPONTE, Being digital, p.14 Itraducción propial. 11 Puede reconocerse que una gran parte de las cualidades estéticas del arte moderno se debió a la influencia que la imagen gráfica tuvo dentro de su desarrollo, tanto por las implicaciones que su creciente presencia prod por ejemplo a través de medios como el cartel desde las últimas décadas de siglo XIX-como por las posibilidades expresivas que sus componentes visuales $y$ verbales otorgaron a medios como la pintura en su liberación de la tradición académica (véase: MORLEY, S. Writing on the wall: word and Image in modern art. Berkeley \& Los Angeles: University of California Press, 2003 224 p.). De aquí que muchos de los puevos valoricos visuales de los medios de la imas sen a astracción la ruptura del espacio lineal, la horizontalidad, ta materialidad del soporte, la geometrí, la tipografía, la hipermediación y otros componentes que formaban parte de las estrategias y recursos de la comunicación gráfica. De esta maner si se observa el creciente desarrollo naturalista e hiperrealista de la image digital, la representación discontinua que influenció la producción pictórica procesos- en movimientos como el cubismo, el futurismo, el expresionismo, el dadaísmo, el constructivismo o el neoplasticismo (al igual que su reconstitución en las segundas vanguardias del siglo XX), contrasta con las "intenciones analógicas" de la primera.

12 De aquí que la cualidad discreta de lo digital no constituya un valor en sí ye con "si hien sus formas expresivas, digitalmente se compone de un número finito de píxeles, a dicha resolución [1200 o 2400 píxeles por pulgadal puede tener mucho mayor detalle de la que jamás fue posible con la fotografía tradicional. Esto anu cualquier diferenciacion entre una 'cantidad indefinida de información en una fotografia de tono continuo' y una cantidad tija de detalle en una p. 100) Como efecto de este orecinte desarrollo tecnológico señalado por Manovich ya desde finales del siglo pasado, en el que la reducción de los elementos de la imagen ha permitido una experimentación continua de su
Sin embargo, esta comprensión antagónica no es suficiente para entender lo que implica una condición digital -o analógica- dentro de los problemas mismos de la expresión visual, dado que de igual manera que una imagen al ser producida o mediada por el computador puede no reconocerse como digital, contrariamente, una imagen producida en medios analógicos puede expresar mayor "digitalidad"11. De hecho, dentro del mismo uso del computador se producen discrepancias en torno a esta ambigüedad, ya que el trabajo a través de software como Photoshop, que fundamenta la producción de la imagen en estructuras discretas de mapas de bits, genera -contrariamente- tendencias expresivas hacia la imagen continua (fotográfica-naturalista) ${ }^{12}$, mientra que la producción en programas vectoriales como lllustrator, que se basan en la continuidad matemática para la generación y manipulación de la forma, generan tendencias expresivas hacia la imagen discreta (gráfica-abstracta).(Fig. 3 .)

Tales contradicciones precisamente señalan que lo analógico y lo digital, como "recursos" de expresión, no son excluyentes ni propios de los medios que los producen. No obstante, pese entonces a que los medios en sí no justifican la naturaleza expresiva de lo analógico o de lo digital, si partimos del principio que "en el ámbito técnico, el término analógico se refiere a cantidades continuas [...] [mientras que] el término digital se refiere a cantidades discretas" ${ }^{13}$, podemos entender que lo analógico se constituye metafóricamente como el sfumato en una pintura, mientras que lo digital lo hace como los recortes en un collage.

Si bien, en los procesos creativos de la imagen usualmente no se pretenden expresar propiamente cantidades, sino más bien ideas, conocimiento o experiencias estéticas -por mencionar algunas razones generales-, este principio, que definitivamente no constituye un asunto nuevo, pero que revalora un criterio de
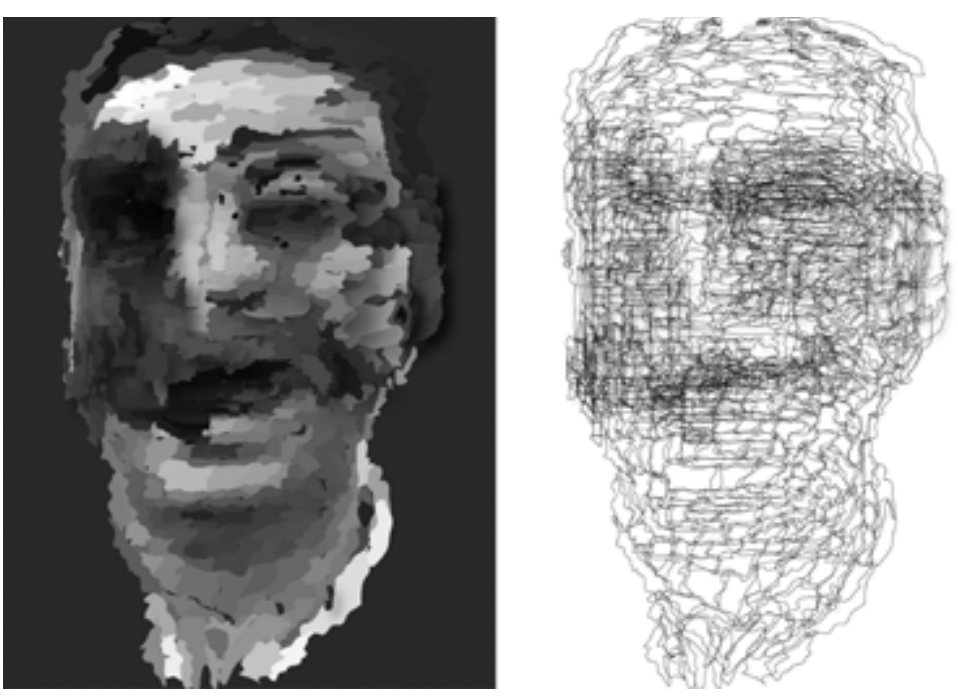

Fig. 3 "Hibridos". Dibujo digital. Bibiana Cárdenas Robayo. 2013
Fig. 4 "Printed Print". La serie "Printed Print," surge de obtener las láminas do acetato que cubre un tambor de una mpresora láser. Estas láminas de su uso, despues de miles de impresiones, han recogido tóner $y$ residuos de proceso, convirtiéndose en auténticas cicatrices de la imagen. En cierta manera es "rido de la magen analogica. Las laminas las escanee y luego crílico. Rubén Tortosa Cuesta. 2013

condición discreta, puede considerarse que el medio digital, dentro de la nado tecnológicamente para devenir expresivamente analógico, aunque ello no implique que haya perdido sus cuaidades expresivas intrinsecas formal como medio, en fundamento, digital. 13 D. I. PORAT, A. BARNA, Introd ción a la tecnología digital, p. 15. 14 R. J. TOCCI, Sistemas digitales: 15 Como según señala Toci. 4 . de los sistemas digitales más conocidos son, a parte de los ordenadores. "las calculadoras digitales, los relojes digitales, los controladores de señales de tráfico y las máquinas de escribir" (p. 4). Sin embargo es en el sistema binario en el que lo digital, como tecnología, ha tenido su mayor desarrollo, ya que por cuestiones técnicas ha sido más "fácil diseñar circuitos electrónicos sólo dos niveles de voltaje" (p. 9) y no con diez, como tendría que hacerse si se basara su tecnología en un sistema numérico digital como el decimal. 16 "Given how important digital technology has become to our lives it is useful to know what the word 'digital' actual means. In technical terms it is used to refer to data in the form of (C) GERE, Digita culture, p. 15). op.cit., p. 97

9 N. NEGROPONTE, op.cit., p. 14 [traducción propia]
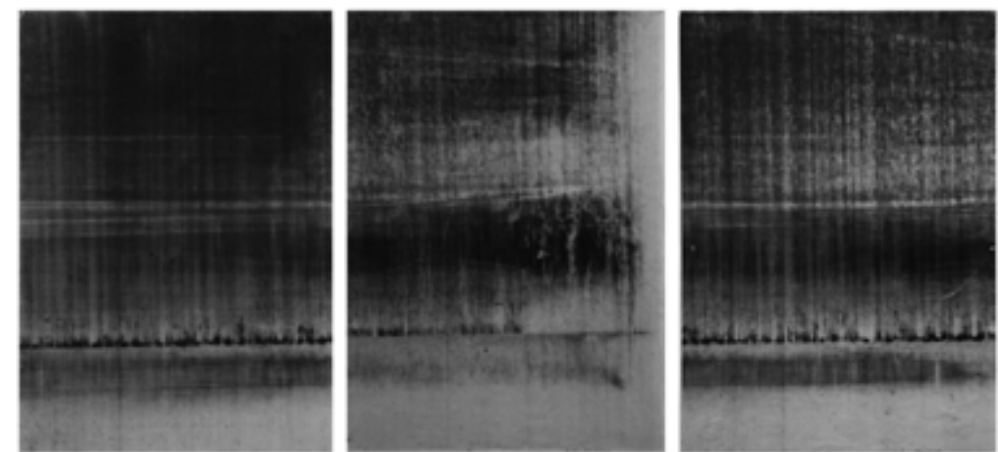

entendimiento en torno a las eventuales propiedades expresivas que pretendan definirse en torno a la imagen visual, propone una diferencia que no se consume en el hecho de identificar lo digital por la denominación de un medio, sino por la manera como expresivamente representa valores. En esta medida, lo digital deja de ser la razón de un único artefacto (el computador) y por lo tanto sus posibilidades como recurso de expresión no se agotan exclusivamente en él, ya que incluso, como sistema digital, si bien el computador constituye un último artefacto tecnológico, no es el único que manipula "cantidades físicas o información que estén representadas en forma digital; esto es, que sólo puedan tomar valores discretos".14 En esta medida, el manejo de cantidades digitales no es propio de un medio electrónico binario sino de cualquiera en el que las cantidades adquieran valores discretos ${ }^{15}$

Puede presumirse entonces que lo digital no está definido exclusivamente por la condición cuantitativa de un sistema -convencionalmente binario-, sino también, y más aun dentro de la exploración aquí propuesta, por una condición cualitativa, donde el sistema binario es solo una posibilidad. Charlie Gere señala que en términos técnicos la palabra "digital" se usa para referirse a datos en forma de elementos discretos, lo cual no implica propiamente una limitación de su concepto a cantidades específicas ${ }^{16}$. Lo digital pese entonces a que comúnmente se asocia como sinónimo de bit, y por lo tanto como sinónimo de computador, fundamentalment puede considerarse que lo es por la manera como cuantifica la información en unidades diferenciadas, constituyéndose fundamentalmente como un "pasar de lo continuo a lo discreto" 17. De hecho, el término "digitalizar" define un proceso a través del cual los datos continuos del "universo analógico" son convertidos en datos o valores discretos, que como bien define Manovich, constituye un proceso que "se compone de dos pasos, que son la toma de muestras y la cuantificación"18. Por ello, se puede entender que lo digital, por naturaleza, se sustenta en una interpretación fundamentada en la abstracción y cuantificación de la realidad, ya que "digitalizar una señal es tomar muestras de ella"19.(Fig. 4.) 
Fig. 5 "Goya 500 (Y no hai remedio)" Intervención digital impresa y ensam-
blada con envases de aspirina. $16 \times 20$ cm. 2006

20 La expresión del medio en la ima gen grafica es también enfatizada por los ruidos que produce sus mecanis mos para la reproducción. Al señala Daniel Giralt-Miracle la revelación que Vins hace de los 'ruidos' que caractesu análisis de la imagen prefotográfica véase: IVINS. W. M. Imagen impresa y conocimiento: análisis de la imagen prefotográfica. Barcelona: Gustavo G 1975. 233 p.) determina que la image gráfica necesariamente produce alteraciones sobre la imagen original cuando es pensada como medio de reproducción. Puede presumirse que tales ruidos son efecto de una necesaria cuantificación, o reducción analógico-a "sistemas de lineas" mediante las que se hace posible reproducción técnica y que dentro de cada sistema de producción gráfica adquiere valores distintos pero que en todo caso se hacen cuantificables, desde la generación de lineas en una xilografía hasta las líneas por pulgad de impresión en semitonos o los pixeles por pulc 21 B. SKRJANEC, "Enfoques múlti22 H. MÍNGUEZ, Gráfica contempora nea, p. 4

23 No solamente la imagen gráfica se ha caracterizado por sus capacidades de abstracción, sino que la cuantificacion se vuelve un asunto elevante en sus procesos creativos productivos. La economía de recursos explorada por el lenguaje grafico, en tivas y reproductivas, conduce a una utilización de recursos que se limita cuantitativamente a las posibilidades capacidades de los medios sobre los que se produce la imagen, como por

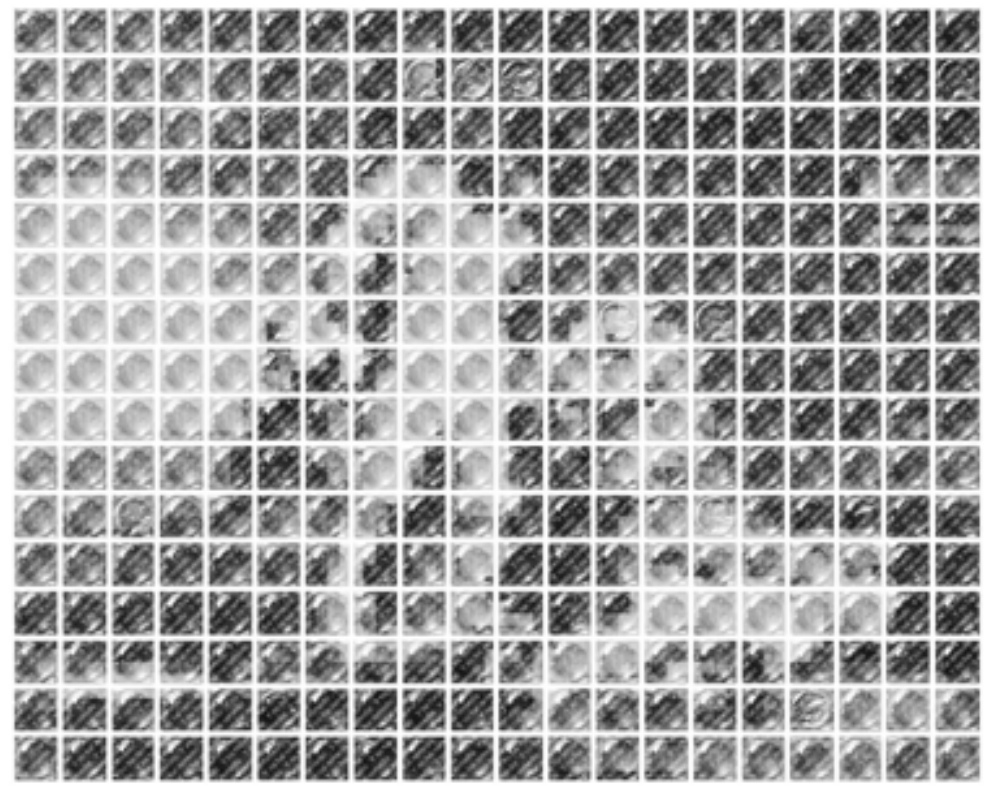

\section{a naturaleza discreta de la gráfica}

Teniendo en cuenta entonces las condiciones sobre las que se comprende lo digital dentro de esta exploración, puede presumirse que conceptualmente la gráfica es digital en cuanto sus formas de producción históricamente han favorecido la abstracción y la cuantificación (o bien, la codificación) en función de sus fines expresivos y comunicativos, tanto desde los procesos de pensamiento que conducen a la conceptualización de la imagen, hasta los procesos de producción que condicionan sus métodos técnicos a los mecanismos de reproducción ${ }^{20}$. Es por ello, que si bien el concepto de "gráfica" puede incluir formas de expresión como el dibujo, será entendido aquí como un lenguaje sustentado en la transferencia de información -de un soporte a otro-, que se manifiesta existencialmente a través de la representación indirecta de la imagen desde cualquier forma de instrumentalización, mecanización o automatización que posibilite su producción multiplicada -así esta no suceda.(Fig. 5 .)

Considerando precisamente que uno de los principales signos del lenguaje gráfico ha sido el de la producción multiplicada, gran parte de su entendimiento como medio expresivo ha estado dirigido primordialmente a asuntos técnicos con base en su reproductibilidad. Sin embargo, pese a que la reproducción puede constituir uno de los principales signos que determina su condición digital, es importante señalar que, dentro de las cualidades visuales de la imagen gráfica, "I duplicación es meramente una potencialidad de la estampa" ${ }^{21}$, por lo que puede pensarse que es dentro del componente de la producción más que el de la reproducción, donde la gráfica encuentra los recursos de mayor identidad de esta condición y sobre lo que se definen tales ejemplo el color. De aqui la reducción y economía de recursos de la image grática, tanto en sus medios tradicionales de producción (e.g. síntesis de información) como dentro de los beneficio de una levedad (conceptuat y fisica) que permita su presencia ubicua desde la producción multiplicad. 24 B. SKRJANEC, op. cit

25 K. CASTRO, "Otros modos de generar imágenes gráficas". En: Mapas invisibles para una gráfica electrónica, p. 30 . 26 La imagen digital puede cons derarse propiamente gráfica, pues al igual que la estampa, se produce indirectamente, solo que, como ya la era mecánica que se desvanece (y a la que perteneció en gran parte la gráfica), "hoy en día la acción y la reacción se producen casi al mismo tiempo" (M. MCLUHAN, op. cit., p. 26). La grática digital que se produce en la pantalla, es matriz e impreso, producción y reproducción, fuente eco simultáneamente. 27 J. MARTÍNEZ MORO, Un ensayo sobre grabado, p. 29

con desde la sustracción -aunque evidentemente existen métodos tanto sustractivos como aditivos, como en el caso del grabado matérico (véase: H. MÍNGUEZ, "Inicios de la gráfica escultórica: el grabado matérico." En Gráfica contemporánea, pp. 51-97), matriz digital, puede decirse, lo hace en principio desde la adición is transferability, which mak i... object of substitution" (M. MELOT "The nature and role of the print" En: Prints: history of an art, p. 23). 30 B. Skrjanec, op. cit

31 De esta manera, siguiendo a Walter Benjamin, puede establecerse una analogia entre el pintor $y$ el artista grafico a partir de la diferenciación que establece entre el actor de teatro $y$ actor de cine. Mientras que el actor tamente, tanto en el medio del cine como del arte gráfico "se interpreta para un aparato". (W. BENJAMIN, La obra de arte en la época de su reproducción mecánica, p.31).

32 R. TOCCl, op. cit., p.5

$33 \mathrm{~J}$. MARTÍNEZ MORO, La ilustra- valores como medio de representación visual, más aun, cuando la eproducción, como experiencia creativa, "ha pasado a ser una opción y no un deber o limitante"22.

El hecho fundamental entonces que pretende rescatarse aquí de la naturaleza reproductiva de la gráfica, es el carácter indirecto que dicha condición implica al desarrollo de la imagen y por lo tanto de los procesos de "digitalización" (muestreo y cuantificación) ${ }^{23}$ sobre los que se constituye. Pensar la imagen reproductible, conduce necesariamente a una interpretación de lo visual que se origina como consecuencia de un componente tanto productivo como reproductivo, definiendo una dualidad intrínseca desde la que se constituye como lenguaje expresivo. Su constitución por lo tanto en esencia "muestra a dos polos opuestos de existencia: el negativo y el positivo" 24 , donde uno es solo posible por el otro o, mejor aún, donde uno no tiene sentido (técnico) si no produce el otro. Tanto el primero como el segundo están asociados respectivamente -pero no excluyentemente - a dos momentos fundamentales, o bien, componentes del lenguaje de la gráfica que aquí podríamos categorizar en dos acciones: producir-originar (hasta el momento que se define la matriz) y reproducir-transmitir (desde el momento que la imagen es duplicada sobre otro soporte); dos momentos que pueden ser entendidos como "el hecho de grabar y el hecho de estampar" 25 , y que por su separación temporal generan una discontinuidad en la creación de la imagen, la cual no solamente se produce sino que necesariamente se reproduce ${ }^{26}$. Esta dualidad no solo forma parte de su proceso creativo, sino que se mantiene latente de manera conceptual dentro de la imagen gráfica durante su existencia como la "multiplicidad de lo único" 27 o la singularidad de lo multiplicable.

Si bien como medio dual la gráfica se constituye fundamentalmente por dos momentos o componentes (producción y reproducción, matriz e impreso), cada uno de ellos puede actuar dentro de una posibilidad binaria, ya que tanto la matriz como el impreso pueden utilizarse expresivamente en la creación visual desde su presencia negativa o positiva. No obstante, lo binario no se presenta solo como efecto de su dualidad productora-reproductora, sino que constituye un principio primigenio de us acciones generativas: quitar y poner ${ }^{28}$; dos posibles operaciones que producen hueco y relieve, vacío y lleno, ausencia y presencia; valores que surgen simultáneamente cuando uno de ellos se provoca.

Esta dualidad del medio gráfico se constituye esencialmente por el carácter indirecto que implica su producción, fundamentando por lo tanto la existencia expresiva de la imagen en la reproductibilidad. De aquí que la imagen gráfica sea un "objeto de sustitución" 29 , ya que su presencia no es efecto de la expresión directa sino de la transferibilidad, motivo por el cual "el pensamiento gráfico es conceptual desde sus mismos comienzos, ya que su esencia se basa en dos fases de pensamiento" ${ }^{30}$ El artista gráfico "actúa" para un mecanismo de reproducción -de forma análoga como lo hace el actor de cine para la cámara ${ }^{31}$, por lo que dentro de su proceso creativo, debe considerar no sólo las cualidades 
Fig. 6 "Print of print." Los trabajos Print
of print de $70 \times 50$, surgen del registro mediante un escáner de fragmentos de otras imágenes. Estos registros los imprimo y transfiero sobre láminas de óleo. Rubén Tortosa Cuesta. 2013

ción como categoría, p. 232. 34 Puede pensarse que la imagen gráfica ha estado determinada por sistemas de lineas que surgen de la $\mathrm{m}$ produce un nuevo sistemedio digital dentro de una matriz intangible, que adquiere forma visual a través del píxel pero que está constituida, o "grabada" por dos estados que toman valores discretos $y$ que en fundamento no se diferencian de la grafica tradicional. 35 P. ISLA, "Más que viejo y menos que nuevo: la estampa digital desde mana perspectiva evoluciontangible, p. 67 .

36 Puede observarse 67. 作 la imagen grática (como estampa real [papell] o virtual [pantalla]) han sido consecuencia implícita de las limitaciones de sus medios. Por ejemplo, las limitaciones del grabado xilográfico en la definición de detalles puede compararse con las limitaciones de la imagen digital en los primeros computadores como producto de la baja resolución de sus pantallas y 'educida capacidad de almacenamiento. imagen, pp. 9-34.

38 M. MELOT, op.cit., p. 9 Itraducción propia]. 39 M. MELOT, op.cit., p. 23 [traduccion propia].

40 M. MELOT, op.cit., Itraducción propia]. Estas cualidades de "ser liviano" "ser portable" y ser "multiplicable, otorgan particularidades especiales su ente como objeto que le permiten enciclopedia o como un museo sin paredes: "Acting as an encycopsin or a 'museum without walls,' the print served to reproduce an impressive number of works, vouching for the power, usefulness and importance of the médium" (op. cit., p.33). A pesar de que el impreso constituye la imagen como materia, las condiciones de su ligereza, movilidad y ubicuidad, dentendidas conceptualmente, la ale BREA, op. cit., p. 39) en la que se inscribe la "imagen-materia" $\gamma$ anticipa a la "imagen-film" (J. BREA, op cit.
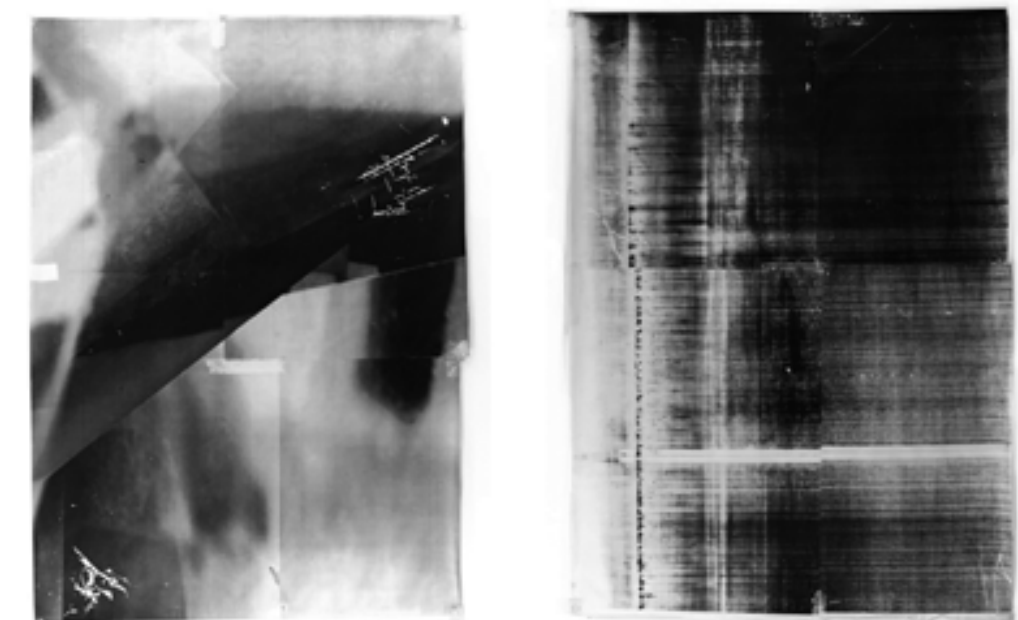

expresivas de los medios a través de los cuales produce la imagen, sino, y sobre todo, las posibilidades que otorgan para poder reproducirlas que son materializadas, principalmente, a través del impreso.(Fig. 6.)

\section{Digital y gráfica}

De acuerdo entonces a este planteamiento, lo digital no será entendido ahora aquí llanamente como la consecuencia de una tecnología que se vincula a un medio, sino sobre todo como una forma de expresión que puede producirse en "el mundo real [que] es fundamentalmente analógico" ${ }^{32}$. Si bien entonces lo digital convencionalmente se ha entendido como una expresión opuesta a lo analógico, las implicaciones adquiridas sobre las que comúnmente se diferencian los nuevos medios de los medios tradicionales -donde lo digital es producto del computador, y lo que no es producto del computador es analógico- no serán entonces ya su fundamento. De esta manera podemos determinar que "lo digital no es estrictamente hablando una propiedad intrínseca de nada, sino la consecuencia de la aplicación de una metodología de interpretación y codificación visual de la realidad"33.(Fig. 7.)

Si consideramos entonces lo digital, ya no exclusivamente como medio de producción, sino también como una cualidad expresiva, podemos asumir que las condiciones necesarias para que se produzca pueden derivarse directamente del entorno creativo y productivo de la imagen gráfica, dado que lo binario y lo discreto -conceptos asociados al lenguaje digital-, constituyen expresivamente valores que se vinculan íntimamente a los procesos separados, discontinuos, cuantificables y constitutivos del lenguaje gráfico. La estructura binaria (ceros y unos) de la matriz intangible, en esta medida corresponde expresivamente desde sus estados (apagado y encendido) a los valores de ausencia y presencia que produce físicamente la matriz tangible ${ }^{34}$-como contenedores de información.

Dadas las cualidades materiales sobre las que se constituye la imagen en el medio digital y el medio gráfico, puede presumirse que
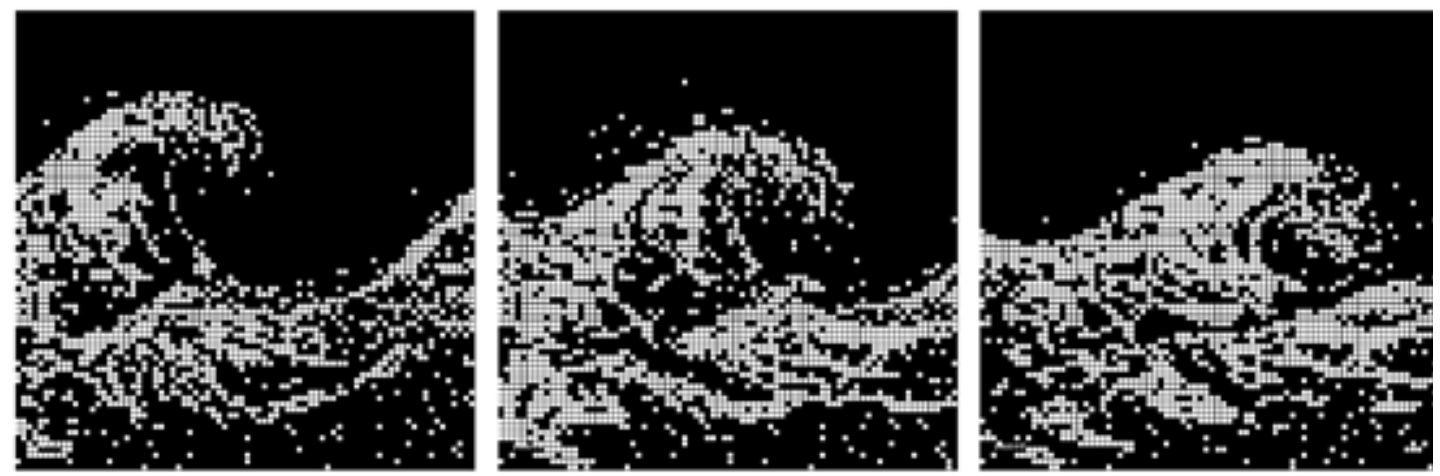

comparte dentro de ellos los mismos intereses existenciales en torno a su presencialidad. En cuanto a la gráfica, puede afirmarse que el impre-

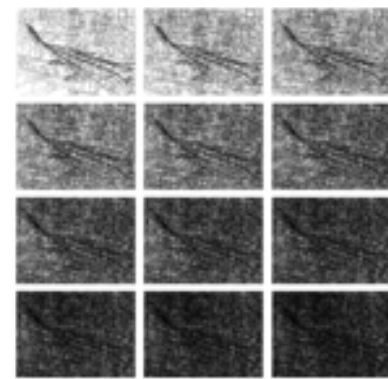

Fig. 7 "Un minuto y medio después construidos en una versión de interfaz gráfica del "Juego de la vida" de John Conway. Fotograma de animación digital. 2 " 10". Ronald Melendez. 201 Fig. 8 "Momento 2' 40"." Dibujo digit vectorial. 12 totogramas de uno de los ración de la instalación audiovisual. Proyección y difusión por Internet. Bibiana Cárdenas Robayo. 2015 de Hokusail" Dibujos basados y

so (o la estampa) ha sido su fin objetual -dado que la multiplicabilidad es un signo de su intención ubicua (diseminadora)-, aunque su constitución material no necesariamente la limita como objeto visual. En cuanto al medio digital, la imagen electrónica, si bien puede materializarse fuera de la pantalla, ésta en sí misma constituye uno de los espacios de su multiplicabilidad. Pepe Isla bien afirma, por ejemplo, que dentro de la gráfica digital "la propia pantalla es también una estampa" ${ }^{35}$, lo cual implica una existencia de la imagen gráfica que no se debe fundamentalmente a una condición física sino conceptual ${ }^{36}$. (Fig. 8.)

Aunque el término "impreso" aluda convencionalmente a la imagen transferida sobre un soporte flexible -usualmente papel -, su concepto, como "imagen-materia" 37 , adquiere ahora entonces connotaciones que trascienden su comprensión como objeto. Melot ya señalaba que la materialidad de la estampa no era necesariamente el papel, pero sí requería "un área flexible, liviana, fácilmente portable" 38 -como la que representa ahora su propiedad electrónica- lo cual implica que sus condiciones objetuales se sustentan principalmente en la movilidad de la imagen y no propiamente en su materialidad. De igual manera, también señala que "lo que constituye una estampa [o impreso] no es el medio o la técnica de la imagen, sino un conjunto de aptitudes a las que debe responder"39, por lo que el impreso, como objeto-imagen, se fundamenta ante todo como "obra de arte portable, una que viaja fácilmente"40.

La imagen gráfica, en su evolución hacia la inmaterialidad, encuentra en la tecnología digital su canal último de producción, más sus cualidades expresivas forman parte histórica de la esencia de su lenguaje. En esta medida, puede decirse que la mirada gráfica supone entonces una "digitalización" del mundo analógico, en cuanto los procesos de abstracción elaborados para la concepción de la imagen, generan necesariamente un muestreo y cuantificación en función de sus intereses informativos, expresivos y difusivos de conocimiento.

Podemos a su vez determinar entonces que la imagen digital en fundamento es gráfica, no solo por su condición indirecta y las posibilidades de multiplicación que otorga como medio técnico, sino por las 
pp. 37-63

41 Si bien es claro que la pixelación man fiesta una de las condiciones expresivas su carácter discreto, no se pretende de terminar que sea su única posibilidad $n$ la más representativa, ya que otras manifestaciones como el error, expresado ex plicitamente a través del glitch art, hacen también evidente la cualidad de un med que, como en el caso de la gráfica, se fundamenta en elementos discontinuos. No obstante, vale la pena recalcar como de la imagen gráfica el pixel art tiene de la imagen grafica el pixel art tiene en de comunicación y creación visual, cuyo origen estético se halla en la apropiación visual de las limitaciones que una vez tuvo el medio, pero que hoy responden evidentemente a una decisión y no a una condición. De hecho, la pantalla - incluso el impreso- deja de ser su único espacio de expresión y se expande hac la materialidad fisica como una adopción de sus valores graficos. Vease por ejenpriasnas de ders.com), los obietos escultóricos de Shinji Murakami (murakamishinii.com) o Shawn Smith (www.shawnsmithart. com), la aplicación en objeto de diseño por Catarina y Luisa Lente (puxxle.yoyo. es), la intervención conceptual en una máscara por Martin Backes (www.mart backes.com) o los mosaicos murales de Kristoffer Zetterstrand (zetterstrand.com Por otro lado, el glitch art, cuya caractersdel error, retoma un hecho que formaba tanto implicita como explícitamente parte ya del lenguaje de la creación gráfica dentro del grabado, fuese por cuestion técnicas, expresivas o conceptuales, tales como el desgaste de la plancha, entintado, los desfases del registro, la variación material de los soportes, etc. Véase por ejemplo la aplicación al diseño textil hecha por Jeff Donaldson (glitcha patrón gráfico.

patrón gráfico.
42 "Though it could refer to almost any system, numerical linguistic or otherwise used to describe phenomena in discrete terms over the last 60 or so years, the word has become synonymous with the technology which has made much of the aforementioned possible, electronic digital binary computers" IC. GERE, op. cit., p.15

43 L. MANOVICH, op. cit., p. 17 cualidades, o como ya se expresó -en términos de Melot-, por las aptitudes sobre las que se constituye existencialmente (levedad, movilidad, ubicuidad, portabilidad) y que evidentemente son potenciadas por el medio digital como mecanismo que representa el punto último de la evolución de la producción gráfica y su progresiva desmaterialización como herramienta de creación.

Como consideración final, dentro de otras posibles cualidades que eventualmente puedan establecerse en torno a las condiciones expresivas que análogamente producen el medio de la gráfica y el medio digital, puede señalarse aquí, además, la evolución similar que en la expresión de la imagen tuvieron ambos medios como consecuencia de las limitaciones de su desarrollo tecnológico hacia la reproducción exacta del mundo visual. En esta medida, la pixelación ${ }^{41}$ de los ocho o menos bits de las primeras gráficas por computador, puede compararse con la tosquedad de las primeras líneas xilográficas, en ambos casos, denotando un desarrollo técnico que pasó de una amplia expresión material del medio hacia su progresiva ocultación.

\section{Lo digital por fuera de "lo digital"}

Sin negar la inevitable vinculación que el término "digital" establece con el computador, es evidente que su concepto evoca no solo un artefacto tecnológico sino también un entorno cultural sobre el que se producen nuevas formas de acción y comportamiento en la generación, procesamiento, almacenamiento y transmisión de la información. Por lo tanto, los asuntos expresivos que se deriven de su tecnología no estarán vinculados solo a sus cualidades como artefacto. Si bien entonces la palabra "digital" se ha convertido en sinónimo de la tecnología que, en palabras de Charlie Gere, ha hecho en gran parte posibles los computadores digitales electrónicos binarios ${ }^{42}$, su incorporación dentro de las dinámicas contemporáneas de producción, no constituye unicamente "maneras de trabajar con datos informáticos, sino maneras generales de trabajar, pensar y existir en la era del ordenador" 43

En esta medida, la expresión de lo digital puede considerarse como un problema que se halla por fuera de los mismos medios que la producen (tanto tradicionales como nuevos), y cuya relevancia como recurso técnico se encuentra en las formas como a través de la imagen interpreta y transmite información. Por ello, desde esta perspectiva, la imagen digital ha sido producto de la abstracción y la reproducción del mundo analógico, cuyos mecanismos de producción, como forma expresiva en torno a la imagen, han sido ya anteriormente mediatizados por el entorno propio de la creación gráfica. Así entonces, podemos hablar de una imagen gráfica que es digital, ya que a través de su lenguaje se ha digitalizado el mundo que representa.

Queda entonces aún por determinar, si en principio consideramos lo digital como algo que no es propio de una tecnología, qué otorga novedosamente su medio a la imagen gráfica como elemento expresivo, o, en otras palabras, queda por cuestionar qué otras cualidades
Ronald F. Meléndez Cardona

Doctorando de la Facultad de Bellas Artes de la Universitat Politècnica de València. Profesor del Departamento de Artes Pontificia Universidad Javeriana Colombial.

Bogotá, Colombia (1977). Actual becario de la Fundación Carolina para estudios de doctorado en la Universitat Politècnica de València. Máster en Producción Artística (UPV énfasis Universidad laverion grática (Pontific logo en Diseño y Producción Gráfica (Unitec, 1998). Artista visual y docente con enfogue hacia la práctica y la investigación del dibujo, la grá́fica y los medios digitales en los ámbitos del arte y el diseño.

\section{Rubén Tortosa Cuesta}

Profesor y Subdirector de Investigación del Dpto. de Dibujo de la Facutad de Bellas Artes de la Universita Politècnica de València

Subdir Belas Artes, es profesor Dpto de Dibuio de la Faculitad de Bellas Artes, Universitat Politècnica de València. Artista de la Galería Set Espai D'Art (Nalencia). Cofundador del grupo artístico Artefactes, con el que ha desarrollado obras electrónicas e instalaciones interactivas. Actualmente participa en un proyec to de investigación, para la creación de un nuevo material de impresión desarrollo de impresora 3D y CNC.

del medio digital permiten que se obtengan nuevas propiedades a la expresión gráfica dentro de lo límites -si los hay- que definen su lenguaje. Las posibilidades de convergencia que dentro del medio digital ha tenido la creación gráfica con otros recursos expresivos, han ampliado progresivamente su existencia como medio múltiple, pero a la vez, puede presumirse que en alguna medida han desvirtuado algunas de sus características propias como lenguaje. A pesar de ello, es claro que no podemos generar una definición única de su concepto, pero vale la pena seguir indagando la gráfica dentro de la época que le corresponde para entender sus posibilidades creativas dentro de las nuevas dinámicas de la comunicación visual.

Bibliografía

ALCALA, JOSÉ RAMÓN. La piel de la imagen: ensayos sobre gráfica en la cultur digital. Valencia: Sendemà, $2011.175 \mathrm{p}$. Gépoca de su reproducción mecática. Madrid: Casimiro, 2010. $60 \mathrm{p}$.

BREA, JOSÉ LUIS. Las tres eras de la imagen. Madrid: Akal, 2010. $142 \mathrm{p}$. CASTRO, KAKO. Mapas invisibles para un gráfica electrónica: (de la huella incisa al grabado con (uz). Vigo: Comanegra, grupo dx5 - Universidad de Vigo, 2007. $228 \mathrm{p}$ GERE, CHARLIE. Digital culture. London: eaktion Books, 2008. 248 p. HAYVAERT, ANNE, CHAUDOUËT, YVES l'empreinte au numérique Vigo: $\mathrm{d}=\mathrm{5}$ Universidad de Vigo / École Européenn Supérieure de l'Image de Angoulême, 2010. 299 p.

ISLA, PEPE. "Más que viejo y menos que nuevo: la estampa digital desde una perspectiva evolucionista". En: SOLER, ANA (COORD.), CASTRO, KAKO (COORD.). La matriz intangible. Vigo: grupo $\mathrm{d} \times 5$ - Univer ad de Vigo, 2004. pp. 60-82 VINS, WILLIAM M. Imagen impresa y cotográfica Barcelisis de la imagen pre$233 \mathrm{p}$.

MANOVICH, LEV. El lenguaje de los nuevos medios de comunicación. Barcelona:

Bernard (ed.). WOLF Mark JP (ed). Th, video game theory reader 2. New York: Routledge, 2009. pp. 370-372

MARTÍNEZ MORO, JUAN. La ilustración como categoría: una teoría unificada sobe
$246 \mathrm{p}$ ander: Creática, 1998. 155 McLUHAN, MARSHALL. La comprensión hombre. México: Diana 1989.443 p. MELOT, MICHEL, ET AL Prints: history of an art. Geneva: Skira, 1988. $279 \mathrm{p}$. MínGUEZ G., HORTENSIA. Gráfica contemporánea: del elogio de la materia a la gráfica intangible. Ciudad Juárez: Universidad Autónoma de Ciudad Juárez, 2012. $419 \mathrm{p}$.

MORLEY, SIMON. Writing on the wall: word and image in modern art. Berkeley \& Los Angeles: University of California Press (

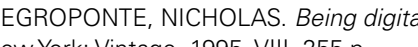
New York: Vintage, 1995. VIII, $255 \mathrm{p}$. J.P. (ed.). The video game theory reader 2. New YORK: ROUTLEDGE, 2009. XXII, $430 \mathrm{p}$.

PORAT, DAN I., BARNA, ARPAD. Introducción a la tecnología digital. México [etc.]: Limusa, $1992.542 \mathrm{p}$

OYNOR, RICK. No más normas: diseño gráfico y posmoderno. México: Gustavo SKRANEC BREDA

En: SOLER, ANA (COORD) "Enfoques múltiples" KAKO (COORD). La matriz intangible, grupo dx5 - Universidad de Vigo, 2004. pp. g2-58

SOLER, ANA (COORD.), CASTRO, KAKO (COORD.). La matriz intangible. Vigo: grupo dx5 - Universidad de Vigo, 2004. $160 \mathrm{p}$. TOCCI, RONALD J. Sistemas digitales: principios y aplicaciones. $5^{a}$ ed., México [etc.]: Prentice Hall
1993. XVI, 823 p. 